\title{
Communications
}

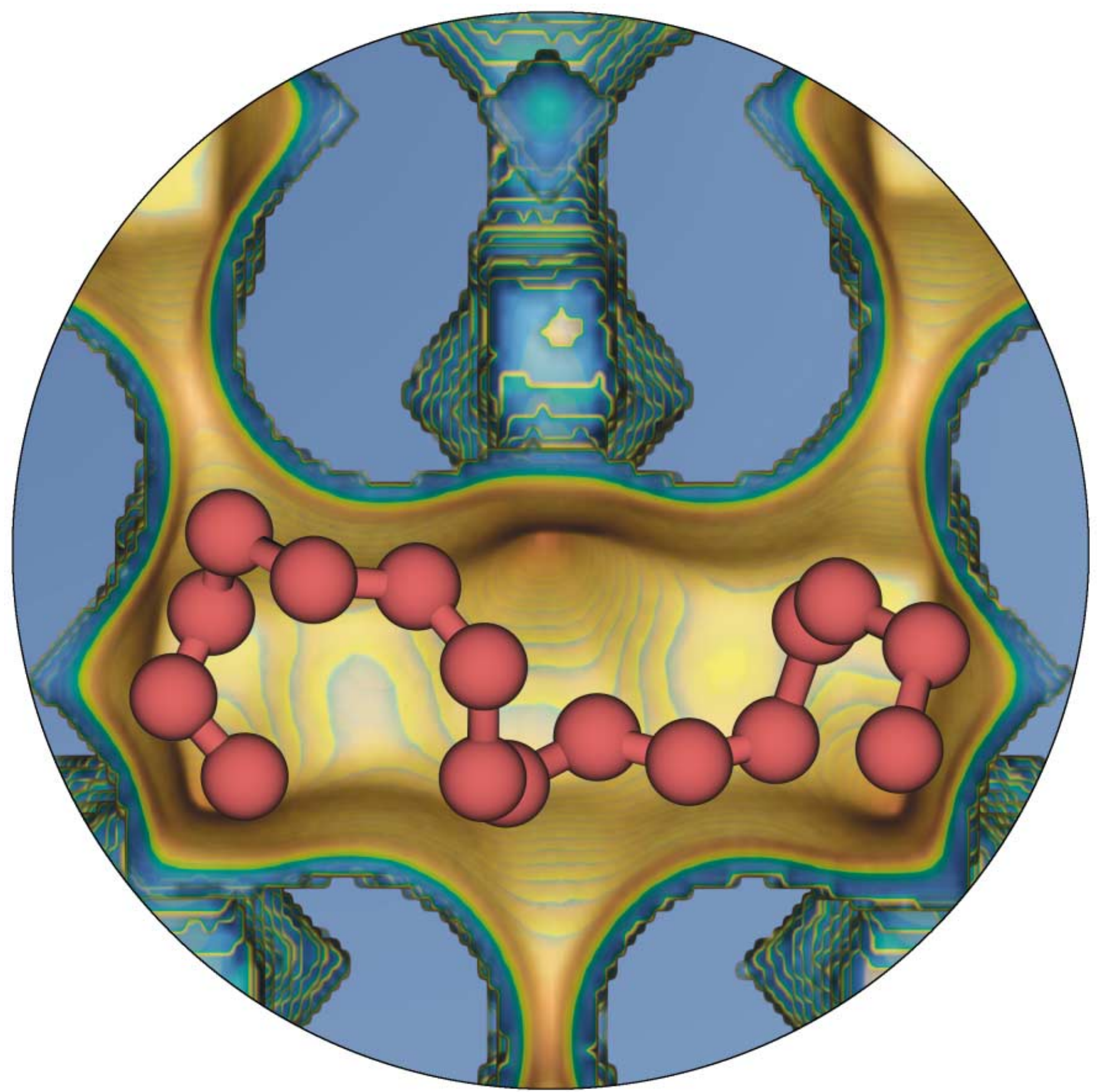

When adsorbates are similar in size to zeolite channels then the surface pores of zeolites only adsorb part of the adsorbate molecule. The not adsorbed section can be cleaved to react further or adsorb elsewhere. This window effect can be examined with the aid of Monte Carlo simulations. For more information see the following Communication by D. Dubbeldam et al. 


\section{Understanding the Window Effect in Zeolite Catalysis**}

\section{David Dubbeldam, * Sofía Calero, Theo L. M. Maesen, and Berend Smit}

The "window effect" is one of the most controversial and intriguing phenomena in the zeolite literature. Chen et al. discovered in 1968 that ERI-type zeolites yield a bimodal product distribution of the products for the zeolite-catalyzed hydrocracking of $n-\mathrm{C}_{21}$ and longer $n$-alkanes, with maxima for the alkanes $n-\mathrm{C}_{3-4}$ and $n-\mathrm{C}_{10-12}$ but no products in the $\mathrm{C}_{5-8}$ range (the window). ${ }^{[1]}$ Conventional zeolite-catalyzed (hydro)cracking yields a product distribution with only a single maximum, which is consistent with the currently accepted reaction mechanisms. ${ }^{[2,3]}$ A comprehensive and fundamental understanding of the product selectivity associated with these catalytic processes is of considerable practical significance, as the results of Chen would open the possibility of length-selective hydrocracking. ${ }^{[4]}$ In the case in which the mandatory addition of volatile ethanol to gasoline is imminent ${ }^{[5-7]}$ the more volatile components that are currently part of gasoline would have to be removed so as to maintain gasoline volatility. This revives the interest in a process that selectively hydrocracks linear pentane and hexane so as to reduce volatility and increase the octane number. Such a process was commercialized in the 1960s, went by the name "selectoforming", ${ }^{[8]}$ and used ERI-type zeolite cages. Improvements on such a process would involve a better understanding of the hydrocracking process of linear alkanes up to a certain chain length. The newly gained understanding affords a prediction of length-selective hydrocracking.

For a long time the window effect has been related almost exclusively to the diffusion rate of $n$-alkanes in ERI-type zeolites. Gorring showed that the product distribution and the diffusion coefficient as a function of $n$-alkane length correlate extremely well. ${ }^{[9]}$ The low diffusion coefficients for $n-\mathrm{C}_{7}$ to $n$ $\mathrm{C}_{9}$ suggest that these molecules diffuse too slowly to leave the zeolite without cracking; the high diffusion coefficients for $n$ $\mathrm{C}_{10}$ to $n-\mathrm{C}_{12}$ suggest that these molecules diffuse rapidly enough to escape. However, recent diffusion measurements by Cavalcante, Jr. et al. ${ }^{[10]}$ and Magalhães et al. ${ }^{[11]}$ failed to

[*] Dr. D. Dubbeldam, S. Calero, B. Smit

Department of Chemical Engineering

University of Amsterdam

Nieuwe Achtergracht 166, 1018 WV Amsterdam (The Netherlands)

Fax: (+31) 20-525-5604

E-mail: dubbelda@science.uva.nl

T. L. M. Maesen

Chevron Texaco, Energy Research and Technology Company Chevron Way 100, Richmond CA 94802-0627 (USA)

$[\cdots *$ We would like to thank the Netherlands Research Council for Chemical Sciences (CW), the European Commission for a Marie Curie Fellowship to S.C., ChevronTexaco for financial support, and C. Wilson, C. H. Roemkens, A. Kuperman, S. I. Zones, and R. Krishna for their comments on our manuscript. reproduce the increase in diffusion coefficient for the appropriate $n$-alkane lengths. This controversy motivated us to simulate the window effect at the molecular level by using advanced molecular simulations. ${ }^{[12-14]}$ In these Configurational-Bias Monte Carlo simulations molecules are grown atom by atom biasing the growth process towards energetically favorable configurations and avoiding overlap with the zeolite. During the growth we calculate the Rosenbluth factor, which is directly related to the excess chemical potential, the free energy, and the Henry coefficient. ${ }^{[15]}$

Although our simulations of the diffusion ${ }^{[16]}$ confirm the experimental observations of Gorring, the results nevertheless point to an alternative mechanism based on the anomalously low adsorption of long molecules. At sufficiently low pressures the amount of adsorbed molecules is directly proportional to the pressure. The proportionality constant is known as the Henry coefficient, and shown in Figure 1 as a

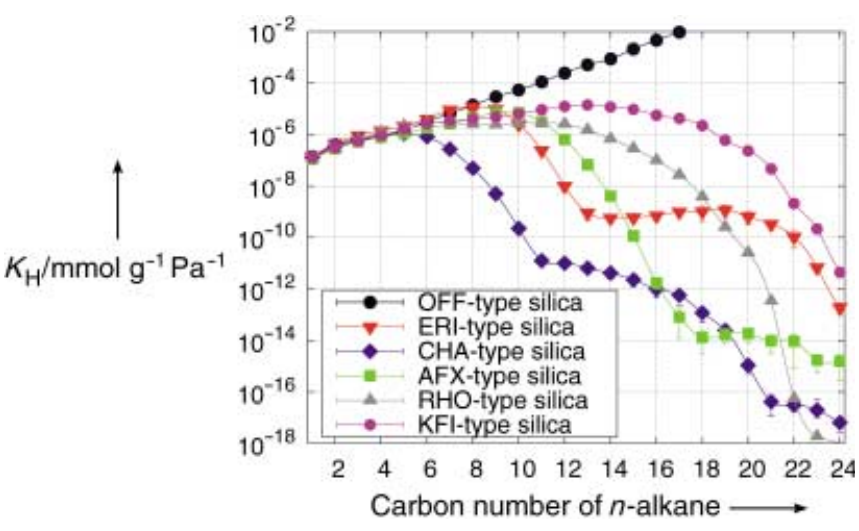

Figure 1. Henry coefficients at $600 \mathrm{~K}$ for various types of zeolites as a function of alkane chain length. At sufficiently low pressures the amount of adsorbed molecules is linearly related to the pressure with the Henry coefficient as the proportionality constant.

function of chain length for various zeolites. OFF-type sieves exhibit the usual monotonic increase of the Henry coefficient with $n$-alkane length. Longer $n$-alkanes have more attractive adsorbent-adsorbate interactions, and-therefore-a lower adsorption enthalpy. Longer $n$-alkanes also have fewer conformations in the adsorbed phase as compared to the gas phase, and-therefore-a lower adsorption entropy. The decrease in enthalpy offsets the decrease in entropy, so that the Gibbs free energy of adsorption decreases (and the Henry coefficient increases) with the lengthening of the $n$-alkane. We found that pores with constrictions (windows) that approach the diameter of the adsorbate exhibit a dramatically different behavior. Instead of attractive adsorbate-adsorbent interactions, these windows exert repulsive adsorbateadsorbent interactions that increase the adsorption enthalpy of any $n$-alkane partially adsorbed inside such a window. Accordingly, the usual compensation between adsorption enthalpy and adsorption entropy ceases as soon as $n$-alkanes become too long to fit comfortably inside the wider part of these pores (cages). For these longer $n$-alkanes the loss of entropy with increasing length dominates their adsorption properties. For example, $n$ - $\mathrm{C}_{13}$ in an ERI-type cage predom- 
inantly adsorbs in a limited number of curled conformations, whereas $n-\mathrm{C}_{14}$ has to stretch through a window into two cages. For even longer $n$-alkanes this pattern is repeated, though now involving a second window. The Henry coefficients of molecular sieves with $<0.45 \mathrm{~nm}$ windows exhibit periodic behavior (Figure 1). The local minima correspond to alkanes that barely fit into $x$ cages, so that alkanes one methylene group longer require $x+1$ cages. Our simulations indicate that all molecular sieves with a window smaller than the $0.45 \mathrm{~nm}$ across EUO-type window exhibit such a remarkable decrease of the Henry coefficient with $n$-alkane length. To the best of our knowledge there are no experimental data available for comparison. In fact, anomalously low adsorption has never been cited when interpreting the catalytic or diffusion data on the large number of zeolites that should exhibit this window or cage effect in adsorption. Below, we amend this situation for ERI- and AFX-type zeolites.

Our simulations for ERI-type zeolite indicate that exactly for $n$ - $\mathrm{C}_{9}$ and longer $n$-alkanes the amount adsorbed decreases. This nicely corresponds with the observed decline in activity, ${ }^{[17]}$ and if we assume that the hydroconversion in ERI is similar to that of zeolites with windows nearly twice as wide (e.g. FAU-type zeolites), this decline may be seen as indirect evidence for our Henry coefficients. The selectivity as observed by Chen ${ }^{[1]}$ concerns $n$-alkanes as long as $n$ - $\mathrm{C}_{36}$. It is important to note that the window effect has become associated only with a high $n-\mathrm{C}_{10-12}$ yield. However, a closer inspection of the raw data of Chen et al. published for $n-\mathrm{C}_{36}$ reveals additional yield maxima at $n-\mathrm{C}_{24-26}$ and at $n-\mathrm{C}_{15-17}$ in the complete chromatogram of the $n-\mathrm{C}_{36}$ cracking products. From the calculated variation of Henry coefficients with chain length it is immediately apparent that the complete $n-\mathrm{C}_{36}$ adsorption can be excluded, and yet ERI-type zeolites crack $n$ - $\mathrm{C}_{36}$ shape selectively. The preferential yield of $n-\mathrm{C}_{24-26}$ and $n-\mathrm{C}_{15-17}$ is indicative of consecutive scissions of $\mathrm{C}_{10-12}$ fragments from $n-\mathrm{C}_{36}$. The maximum at $n-\mathrm{C}_{10-12}$ indicates that the most rapidly diffusing cracking product can escape complete consumption into more refractory alkanes with six or fewer carbon atoms. This selective cracking process leaves minima at $n-\mathrm{C}_{18-23}$ and at $n-\mathrm{C}_{13-14}$. A reasonable explanation for the persistence of shape-selective cracking of very long alkanes by ERI-type zeolites is that these long molecules adsorb partially in the surface pockets created by the ERI-type cages at the outer crystal surface. Full adsorption by more than 12 carbon atoms is unlikely. The adsorbed $n$ - $\mathrm{C}_{10-12}$ part is chopped off, and the nonadsorbed part is released. The released parts end up in the product slate or undergo further scission reactions. This process becomes less selective with an increasing number of cracking steps because of concomitant isomerization reactions. AFX-type zeolites exhibit a hydrocracking pattern similar to ERI-type zeolites. This is not surprising, as these zeolites only differ in the size of the cages. Similar to ERI-type zeolites, ${ }^{[4]}$ AFX-type zeolites preferentially hydrocrack shorter rather than longer $n$-alkanes ${ }^{[18]}$ when given a choice. Thus, they consume exclusively $n-\mathrm{C}_{6}$ when processing a mixture of $n-\mathrm{C}_{6}$ and $n-\mathrm{C}_{16}$, even though they hydroconvert more than $50 \%$ of either $n-\mathrm{C}_{6}$ or $n-\mathrm{C}_{16}$ when processing them separately. Inspection of our Henry coefficients shows that $n-\mathrm{C}_{6}$ adsorbs fully, whereas $n-\mathrm{C}_{16}$ can only adsorb partially. As partial adsorption is thermodynamically highly unfavorable ${ }^{[19]}$ fully adsorbing molecules can effectively block adsorption and hydroconversion for partially adsorbing molecules. Naturally, windows approaching the diameter of the adsorbate are a barrier to both adsorption and diffusion, and these two factors cannot be seen in isolation. Diffusion rates determine the impact of the very low adsorption on catalysis. Its impact will be higher when the diffusion is slower, because the path through consecutive windows is highly tortuous (as in ERI-, AFX-, and CHA-type zeolites). Its impact will be lower when the diffusion is faster because the path through consecutive windows is straight (as in RHO- and KFI- type zeolites) (Figure 2). This newly gained understanding of length-selective hydrocracking affords a prediction of selectivity as a function of cage size. We would predict that the larger AFX-type cage shifts the cracking selectivity by two carbon atoms towards longer $n$ alkanes as compared to the smaller ERI-type cage, and that
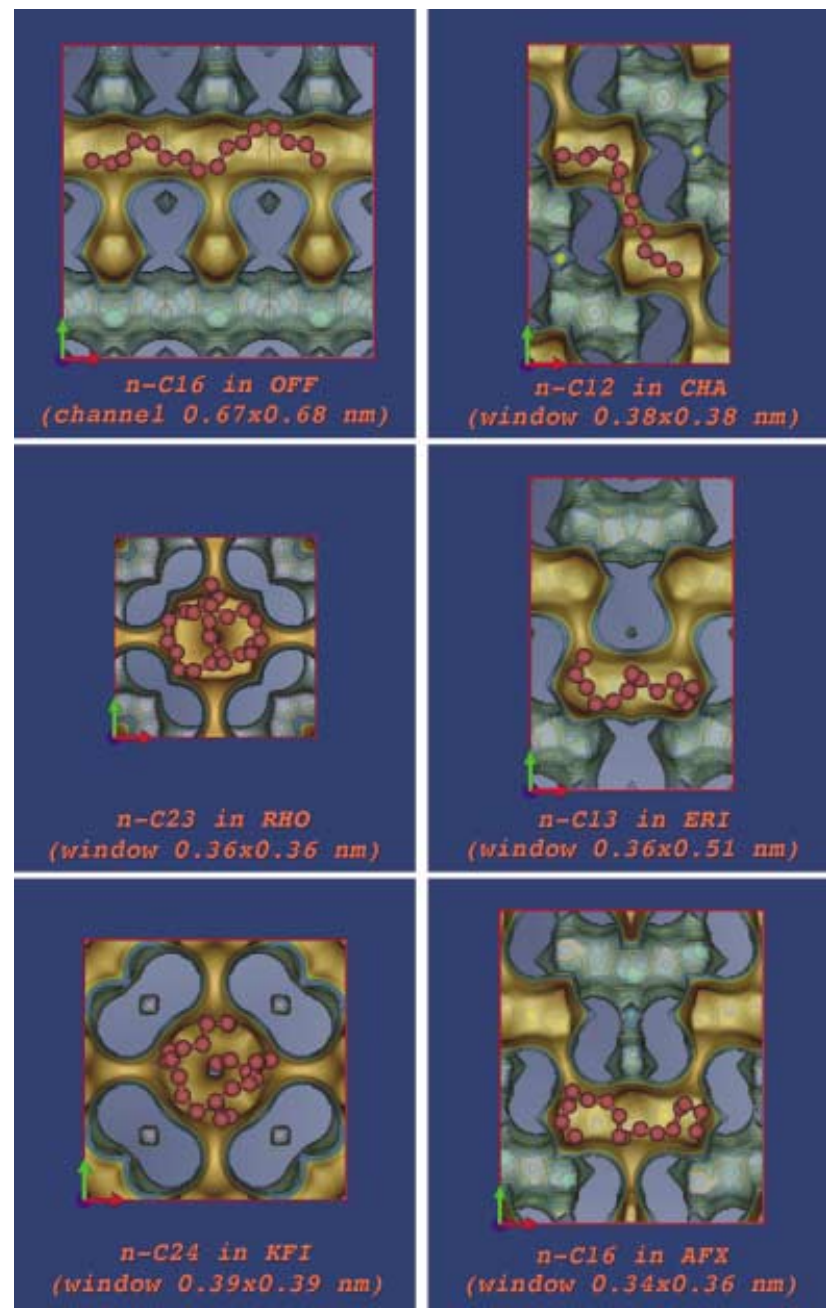

Figure 2. The crystalline structures OFF-, ERI-, RHO-, CHA-, KFI-, and AFX-type zeolites. The size of the $\mathrm{CHA}$-, ERI-, and AFX-type cages limit the $n$-alkanes to 11,13 , and 16 carbon atoms, respectively. The large cages of RHO- and KFI-type zeolites accommodate molecules up to $n$ $\mathrm{C}_{24}$ and $n-\mathrm{C}_{26}$, respectively, in snake-in-a-basket conformations. The red balls represent $\mathrm{CH}_{3}$ - or $\mathrm{CH}_{2}$-groups. Arrows at the origin are $0.3 \mathrm{~nm}$ in length. 
the even smaller CHA-type cages shift the cracking selectivity further towards $n-\mathrm{C}_{5}$. We further predict that RHO- and KFItype zeolites afford length-selective hydrocracking of $n$ alkanes longer than those removed by AFX-type zeolites.

In summary, we refute some of the traditional cracking mechanisms found in zeolite literature based on full adsorption. The simulation results indicate abnormally low adsorption in ERI-, AFX-, CHA-, RHO-, and KFI-type zeolites for chain lengths close to or longer than the cage size. Hence, very long molecules adsorb partially into a cage near the outer surface. After scission the nonadsorbed part can end up in the product or re-adsorb and undergo another scission. This mechanism is characteristic for cage/window-type zeolites with small windows close to the diameter of the adsorbate. The newly gained understanding of length-selective hydrocracking affords prediction of selectivity as a function of cage size.

Received: February 5, 2003 [Z51110]

Keywords: alkanes · catalysis · computer chemistry · cracking · zeolites

[1] N. Y. Chen, S. J. Lucki, E. B. Mower, J. Catal. 1969, 13, 329-332.

[2] J. Weitkamp, S. Ernst, L. Puppe in Catalysis and Zeolites (Eds.: J. Weitkamp, L. Puppe), Springer, Berlin, 1999, pp. 326-376.

[3] J. A. Martens, P. A. Jacobs in Zeolite Microporous Solids: Synthesis, Structure, and Reactivity (Eds.: E. G. Derouane, F. Lemos, C. Naccache, F. Ramão-Ribeiro), Kluwer, Amsterdam, 1992, pp. $511-529$.

[4] J. Wei, Ind. Eng. Chem. Res. 1994, 33, 2467-2472.

[5] M. Radler, Oil Gas J. 2002, 100, 5-9.

[6] K. Watkins, Chem. Eng. News 2001, 79(30), 21-21.

[7] M. Lorenzetti, Oil Gas J. 2003, 101, 20-22.

[8] N. Y. Chen, J. Maziuk, A. B. Schwartz, P. B. Weisz, Oil Gas J. 1968, 66, 154-157.

[9] L. R. Gorring, J. Catal. 1973, 31, 13-26.

[10] C. L. Cavalcante, Jr., M. Eić, D. M. Ruthven, M. L. Occelli, Zeolites 1995, 15, 293-307.

[11] F. D. Magalhães, R. L. Laurence, W. C. Conner, AIChe. J. 1996, $42,68-86$.

[12] B. Smit, T. L. M. Maesen, Nature 1995, 374, $42-44$.

[13] T. J. H. Vlugt, R. Krishna, B. Smit, J. Phys. Chem. B 1999, 103, $1102-1118$.

[14] T. L. M. Maesen, M. Schenk, T. J. H. Vlugt, J. P. de Jonge, B. Smit, J. Catal. 1999, 188, 403-412.

[15] D. Frenkel, B. Smit in Understanding molecular simulation, 2nd ed., Academic Press, London, UK, 2002.

[16] D. Dubbeldam, S. Calero, T. L. M. Maesen, B. Smit, Phys. Rev. Lett. 2003, 90, 245901.

[17] N. Y. Chen, W. E. Garwood, Adv. Chem. 1973, 121, 575-582.

[18] D. S. Santilli, S. I. Zones, Catal. Lett. 1990, 7, 383-387.

[19] E. B. Webb III, G. S. Grest, J. Chem. Phys. 2002, 116, 6311-6321. 